\title{
Iris prosthetic IOL implantation after strabismus surgery and 4-year follow-up in a case of long- standing traumatic aniridia
}

\begin{abstract}
I report here a 32 years old aphakic male patient with external strabismus and traumatic subtotal temporal aniridia in the right eye. Visual acuity was counting fingers from 2 meters and intraocular pressure (IOP) was $12 \mathrm{mmHg}$ in this eye. He exhibited -18 prism diopter exophoria with a clear cornea and open visual axis, but only showed a half intact iris on the nasal side. No posterior segment pathology was detected during fundus and ultrasonographic examinations. Initially, I performed 6-mm resection of the medial rectus muscle for his external squint in January 2012; then I performed iris prosthetic scleral intraocular lens implantation in October 2012. Even on the postoperative first day, the patient was happy with his new vision and outlook. His visual acuity was $12 / 20$ and IOP was $24 \mathrm{mmHg}$. His last examination was performed in October 2017; his final visual acuity was $16 / 20$ and IOP was $18 \mathrm{mmHg}$.
\end{abstract}

Keywords: traumatic aniridia, aphakia, iris prosthetic intraocular lenses, recovery of visual disturbances
Volume 8 Issue 2 - 2018

Cuneyt Karaarslan

World EyeHospital Adana, Turkey

Correspondence: Cuneyt Karaarslan, World EyeHospital Adana,Turkey, Tel +90 533 731 7273, Email cuneyt.karaarslan@dunyagoz.com

Received: February 25, 2018 | Published: March 21, 2018

\section{Introduction}

Post-traumatic iris defects, combined with crystalline lens abnormalities, are among the major complications of globe injuries. ${ }^{1}$ Individuals who lack adequate iris tissue suffer from glare, photophobia, visual field disturbances, and other visual disturbances that can cause social, mental, and psychological problems. ${ }^{2}$ Such patients suffer from severe visual impairment, secondary to aphakia. ${ }^{3}$ Herein, I describe an approach for the management of an aphakic, exophoric eye with traumatic aniridia, which was found in a patient who underwent transscleral fixation of an artificial iris prosthetic intraocular lens (IOL), 10 months after strabismus surgery.

\section{Case report}

The patient was a 32-year-old aphakic male who had exhibited traumatic subtotal temporal aniridia and divergent strabismus in the right eye since the age of 13. I first examined him in 2012; his visual acuity was counting fingers from 2 meters, while the intraocular pressure (IOP) was $12 \mathrm{mmHg}$ in this eye. He exhibited -18 prism diopter exophoria and a mostly clear cornea. He also exhibited an open visual axis with a temporal loss of nearly half of the iris. No pathology was detected in the posterior segment during direct fundus examination, ultrasonography, or optical coherence tomography. Initially, I performed a 6-mm medial rectus muscle resection on the right eye to correct his divergent strabismus in January 2012. Ten months after this operation, his Ophtec 311 Aniridia Lens II arrived at our clinic.

Under general anesthesia, two conjunctival limbal-based trigonal flaps were made at the 3 and 9 o'clock meridians before performing a superior $9.7 \mathrm{~mm}$ clear corneal incision. After hitching the 9-0 polypropylene looped sutures with a long-curved needle (PC-9; Alcon Surgical, Fort Worth, TX, USA) to the haptic of iris prosthetic polymethyl methacrylate IOL, the haptics were tightly attached. After passing the needles through the marked scleral points, the
IOL was implanted and retracted, such that it was stabilized and well-centered after the withdrawal of both needles through the pars plana. Polypropylene sutures were tied to the sclera, and the suture knots were buried into the sclera on both sides. To ensure placement within the sclera, the suture ends were buried along with the knots. The corneal incision was sutured with a 10-0 non-absorbable nylon suture, while the conjunctiva was subsequently closed with an 8-0

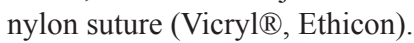

Even on the postoperative first day, the patient was happy with his new vision and outlook. His visual acuity was $12 / 20$, while his IOP was $24 \mathrm{mmHg}$. He demonstrated a significant astigmatism $(-2.75 \mathrm{x} 155)$. His last examination was conducted in October 2017; his visual acuity was $16 / 20$ and his IOP was $18 \mathrm{mmHg}$. His autorefractometry was $-0.75(-0.75 \times 165)$ and he was thankful and pleased to function without glasses (Figure 1-4).

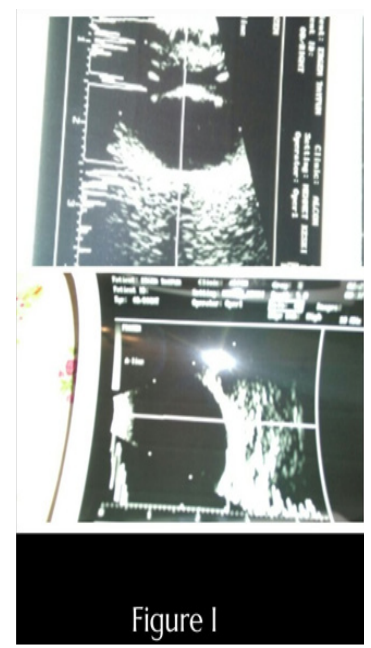

Figure I Pre- and post-operative ultrasonography. 


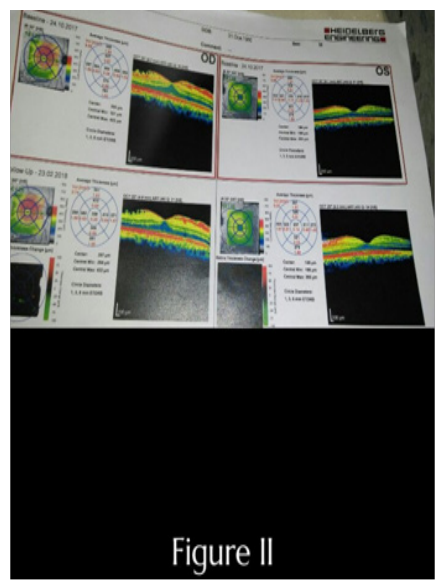

Figure 2 Pre- and post-operative optical coherence tomography.

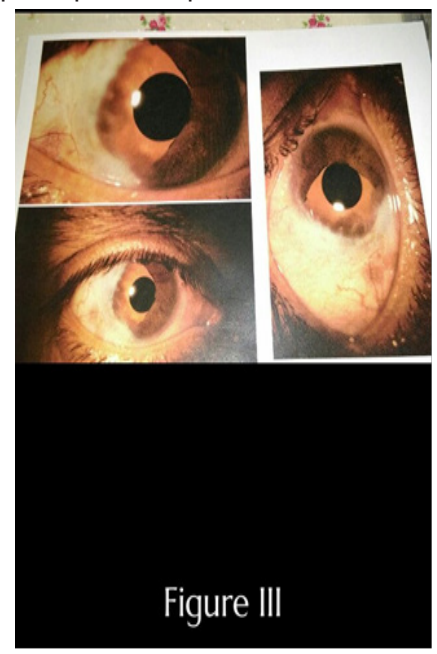

Figure 3 Iris prosthetic intraocular lens.

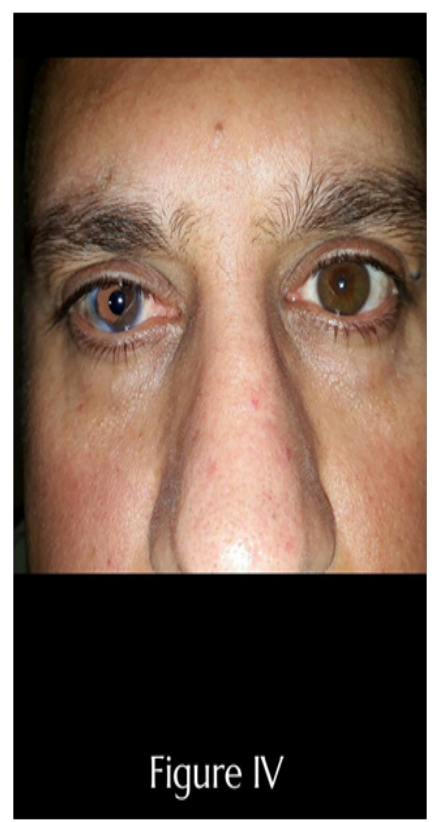

Figure 4 Final outcome.

\section{Discussion}

Iris defects combined with aphakia are serious problems that are frequently encountered after globe injuries. ${ }^{4,5}$ Aside from aesthetic aspects, partial or total loss of iris tissue may also contribute to various degrees of glare, photophobia, and visual impairment. ${ }^{6,7}$ In patients with major iris defects, an artificial iris prosthesis provides satisfactory anterior segment reconstruction with remarkable visual and functional outcomes. ${ }^{8}$ Various implants have been developed for the treatment of aphakia with aniridia, such as the Morcher black-diaphragm IOL (Morcher 67F BDI, Morcher). The Ophtec iris reconstruction lens (Ophtec USA, Boca Raton, FL, USA), with the color options of brown, blue, and green, has been reported to provide better cosmetic outcomes, as well as remarkable visual improvements. ${ }^{9,10} \mathrm{~A}$ lack of effective iris tissue or pigmentation allows excess light into the eye, causing both photophobia and an inability to open the eye normally. ${ }^{11}$ These patients suffer from image degradation because of an increase in higher order aberrations in the optical system that occur with increased pupil size. A fixed 4-mm pupil size of Ophtec 311 IOL decreases these visual disturbances, thus improving visual acuity, in a manner that combines with its provision of pseudophakic diopteric advantages. ${ }^{12,13}$

\section{Conflicts of interest}

No financial support was received for this study.

\section{Acknowledgments}

None.

\section{References}

1. Villemont AS, Kocaba V, Janin-Manificat H, et al. Management of post-traumatic aphakia and aniridia: Retrospective study of 17 patients undergoing scleral-sutured artificial iris intraocular lens implantation. Management of aphakia-aniridia with scleral-sutured artificial iris intraocular lenses. J Fr Ophthalmol. 2017;40:592-605.

2. Mostafa YS, Osman AA, Hassanein DH, et al. Iris reconstruction using artificial iris prosthesis for management of aniridia. Eur J Ophthalmol. 2017;28(1):103-107.

3. Weissbart SB, Ayres BD. Management of aniridia and iris defects: an update on iris prosthesis options. Curr Opin Ophthalmol. 2016;27(3):244 249.

4. Mayer CS, Reznicek L, Hoffmann AE. Pupillary reconstruction and outcome after artificial iris implantation. Ophthalmology. 2016;123(5):10111018 .

5. Srinivasan S, Ting DS, Snyder ME, et al. Prosthetic iris devices. Can J Ophthalmol. 2014;49(1):6-17.

6. IV Zapuskalov, OI Krivosheina. Current trends of reconstructive surgery of traumatic damages of anterior segment of the eye. Oftal'mokhirurgiya. 2013;2:59-61.

7. Thomas BC, Rabsilber TM, Auffarth GU. Aniridia-IOL and artificial iris reconstruction. Klin Monbl Augenheilkd. 2013;230(8):786-790.

8. De Grande V, Rosenthal K, Reibaldi M, et al. Artificial iris-intraocular lens implantation for traumatic aniridia and aphakia assisted by silicone oil retention sutures. J Cataract Refract Surg. 2012;38:2045-2048.

9. Roman $\mathrm{S}$, Cherrate H, Trouvet JP, et al. Artificial iris intraocular lenses in aniridia or iris deficiencies. J Fr Ophthalmol. 2009;32(5):320-325. 
10. Trivedi RH, Wilson ME. Aniridia and Cataracts. Pediatric Cataract Surgery 2005.

11. Krader CG. Iris reconstruction lens benefits. Ophthalmology Times 2011.

12. Burk SE, Da Mata AP, Snyder ME, et al. Prosthetic iris implantation for congenital, traumatic, or functional iris deficiencies. J Cataract Refract Surg. 2001;27(11):1732-1740.

13. Beekhuis WH, Drost BH, van der Velden/Samderubun EM. A new treatment for photophobia in posttraumatic aniridia: a case report. Cornea. 1998;17(3):338-341. 